\title{
Applying Mass Communication Theory to Bystander Intervention in Bullying
}

\author{
Amanda B. Nickerson ${ }^{1}$ Thomas H. Feeley ${ }^{2} \cdot$ Mina Tsay-Vogel $^{3}$
}

Received: 5 February 2016/Accepted: 13 May 2016/Published online: 30 May 2016

(C) Springer International Publishing 2016

\begin{abstract}
Bystander behavior in bullying has received increasing attention in the literature, but it is seldom grounded in a strong theoretical context and rarely draws from multiple disciplines. The current article proposes how theory in mass communication can aid research efforts seeking to better understand and prevent bullying through bystander intervention. This article first provides an overview of the research on bystanders in bullying and uses Latané and Darley's (The unresponsive bystander: why doesn't he help? Prentice Hall, Englewood Cliffs, 1970) classic bystander intervention model as an organizing framework. Next, mass communication theory, with its focus on the strategic use of messaging to affect attitudes and behaviors, is reviewed. Theory and research in communication relevant to the prevention of bullying is then discussed, with particular attention to the bystander intervention model. The article concludes with recommendations for how future research and interventions grounded in communication and psychology may advance our understanding and encouragement of adolescent bystander intervention behavior in bullying.
\end{abstract}

Amanda B. Nickerson

minatv@bu.edu

1 Alberti Center for Bullying Abuse Prevention, Counseling, School, and Educational Psychology, University at Buffalo, The State University of New York, 428 Baldy Hall, Buffalo, NY 14260-1000, USA

2 Department of Communication, University at Buffalo, The State University of New York, 354 Baldy Hall, Buffalo, NY 14260-1000, USA

3 Mass Communication, Advertising, and Public Relations, Boston University, 640 Commonwealth Avenue, Boston, MA 02215, USA
Keywords Bystander intervention - Mass communication · Bullying

\section{Introduction}

The problem of bullying in youth has received unprecedented attention in the media, legislation, and in the research literature in the past decade (Nickerson et al. 2013; Stuart-Cassel et al. 2011). Bullying is defined as unwanted aggressive behavior(s) by another youth or group of youth that involves an observed or perceived power imbalance and is repeated or highly likely to be repeated (Gladden et al. 2014). Bullying can be direct or indirect, and may include forms such as physical, verbal, relational, and property damage. It also occurs across contexts, including electronically (e.g., cyberbullying), and may result in physical, psychological, social, or educational harm or distress on the targeted youth (Gladden et al. 2014). The peer context surrounding bullying and the importance of bystander intervention are becoming better understood (see e.g., Salmivalli 2010), yet research and intervention can be further advanced using a theoretically grounded and multidisciplinary approach.

In this article, we briefly review bullying and the peer context, interventions involving peers, and the role of bystanders in bullying. We then detail Latané and Darley's (1970) bystander intervention model based on decades of social science theory and research, applying it to bullying. To exemplify the importance of integrating work of other disciplines, the field of mass communication is overviewed, highlighting several theories relevant to bystander intervention in bullying. Finally, ideas for future research and intervention advances that integrate theory and contributions from mass communication are provided. 


\section{Bullying and the Peer Context}

The social influences surrounding bullying behavior appear to change rather dramatically from childhood to adolescence. As youth progress through early adolescence (sixth through eighth grades), peers become a greater source of influence and support (Nickerson and Nagle 2005). However, bullying tends to peak in middle school (Unnever and Cornell 2004; Wang et al. 2009), at the same time students are less likely to help a peer who is targeted by bullying (Batanova et al. 2014; Endresen and Olweus 2001; Jeffrey et al. 2001). A closer examination of developmental trends in bullying reveals that direct, observable aggression declines from $80 \%$ of bullying in 6th grade to just over $50 \%$ in 12th grade, whereas indirect, less observable bullying increases from just over $60 \%$ of bullying in 6th grade to approximately $75 \%$ of bullying by 12 th grade (Yeager et al. 2015). Therefore, some forms of bullying continue to be an issue in adolescence, and the power of the peer group during this time is evident.

By early adolescence and continuing into high school, bullying and other peer-directed hostile and aggressive behaviors are strongly associated with moderate to high social status (Faris and Felmlee 2011; Juvonen and Graham 2014). Boys with aggressive behaviors become more accepted in adolescence, and are perceived as "cool" (Rodkin and Hodges 2003). For the majority of adolescents, increases in status are accompanied by increases in aggression (Faris and Felmlee 2011), and bullying may be used strategically to improve social standing (Bibou-Nakou et al. 2012; Juvonen and Graham 2014). Findings from a social network analysis of students in 8th, 9th, and 10th grades found the highest rates of school-based victimization (i.e., being picked on or someone being mean; not necessarily bullying) occur among students with relatively high social standing, suggesting that victims are often close status rivals as opposed to more isolated targets (Faris and Felmlee 2014). Girls were also more likely to be victims (from both boys and girls), and the victimization seems to spread through groups of friends (Faris and Felmlee 2014). Similarly, social network analysis has revealed that adolescents select friends based on similar levels of instrumental aggression (Sijtsema et al. 2010).

\section{Intervention Approaches Involving Peers}

These developmental trends in bullying may explain why a recent meta-analysis found that although bullying prevention programs showed some effectiveness for youth in grades 7 and below, these results were nullified in grade 8, and were even harmful in grades 9-12 (Yeager et al. 2015). It has been asserted that anti-bullying interventions for adolescents should consider how aggressive behaviors are rooted in status processes (Faris and Felmlee 2011, 2014).

Because bullying is conceptualized as a social event that is implicitly and explicitly supported by peers (Jones et al. 2012; Salmivalli and Voeten 2004) and used as a way to achieve higher social status (Juvonen and Graham 2014), intervention approaches that can harness the influence of powerful youth toward more prosocial goals and norms are needed. Middle and high schools have implemented schoolbased social norms campaigns aimed at a variety of issues, such as reducing rumor spreading (Cross and Peisner 2009), alcohol consumption (Hughes et al. 2008), and rape-supportive behaviors (Hillebrand-Gun et al. 2010). In addition, Perkins et al. (2011) conducted a case study experiment of a social norms intervention to target bullying prevention in five public middle schools, which resulted in significant reductions in perceptions of peer bullying, pro-bullying attitudes, personal bullying of others, and victimization. These approaches have also been used with social referents (e.g., popular students, clique leaders), as in the "Names Can Really Hurt Us" (NAMES) intervention (Paluck and Shepherd 2012). In NAMES, social referent students presented their experiences of harassment and reasons to oppose harassment in a school-wide assembly, which led to changes in prescriptive norms to be more prosocial related to peer conflict and harassment.

There is also interest in mobilizing bystanders to intervene directly or indirectly to stop bullying. This is based on the idea that favorable social feedback allows bullies to feel good about themselves and perhaps to discount the harm they inflict on others (Juvonen and Graham 2014). In contrast to Yeager et al. (2015) findings of lower effects of bullying prevention programs for adolescents, Polanin et al. (2012) meta-analysis of school-based programs that emphasized changing bystander intervention behavior revealed that samples with high school students only showed greater treatment effects compared to elementary schools only. Although this study was based on only 12 comparisons, it provides some evidence that interventions which seek to shift attitudes and behaviors to support bystander intervention may be a promising approach with adolescents. This is an area ripe for future research and interventions, drawing on a strong theoretical approach and incorporating the work of other disciplines.

\section{Latané and Darley's (1970) Bystander Intervention Model: Applications to Bullying}

Despite the growing interest in the role of the bystander in bullying, most research in this area is not situated within the theoretically grounded process of bystander intervention in emergency situations, which has been the focus of 
social psychological research for over four decades. This research has focused on the bystander effect, or the inhibiting effects of the presence of others on helping behavior (Dovidio et al. 2006; Darley and Latané 1968). Building on the empirical research in this area, Latané and Darley's (1970) bystander intervention model outlined five sequential steps that one must take in order to take action: (a) notice the event (e.g., Is this bullying?), (b) interpret the event as an emergency that requires help (e.g., Is this student in need?), (c) accept responsibility for the situation (e.g., Is it my place to help?), (d) know how to intervene or provide help (e.g., What do I do?), and (e) implement the intervention decision (e.g., Help or don't act?). Although the measurement of this model has only been validated recently as applied to bystander intervention in bullying and sexual harassment (see Nickerson et al. 2014), it has been applied to helping behavior in contexts such as drunk driving (Rabow et al. 1990), sexual assault prevention (Burn 2009), and organ donation (Anker and Feeley 2011). Each step of the model is described below, integrating findings about influences on each step from the social psychology literature, as well as how this may apply to issues more specific to bullying.

\section{Step 1: Notice the Event}

In order for helping to occur, one must first focus his or her attention to the event. Perceptions of an event's occurrence directly or indirectly (through other steps in the bystander intervention model) predict intervention (Greitemeyer et al. 2006). Research with the bystander intervention in both emergency and prosocial situations has revealed that vivid events, or those with specific, identifiable victims, are more likely to draw bystanders' attention (Dovidio et al. 2006; Loewenstein and Small 2007). Focusing on pressing priorities or environmental stimuli (e.g., noise, other people) decreases the likelihood that someone will notice an event that may require help (Burn 2009; Dovidio et al. 2006). Given the relatively high prevalence of bullying in schools (Dinkes et al. 2009; Wang et al. 2009), it is likely that youth may not attend to relevant cues (e.g., use of derogatory names, excluding) or view them as vivid events. Recent research on the bystander intervention model in cyberbullying reveals that noticing the event is critical, in that the likelihood of intervening directly or indirectly is 4.62 times greater if the bystander notices the cyberbullying (Dillon and Bushman 2014).

\section{Step 2: Interpret the Event as an Emergency that Requires Help}

Once someone notices an event, he or she must interpret it as an emergency worthy of help or intervention (Latané and Darley 1970). Classic studies (e.g., Darley and Latané 1968) show that pluralistic ignorance (i.e., people looking to other bystanders for information about a situation before they label it as an emergency) leads to errors in decisionmaking. For example, in a seminal study where participants were asked to wait (either alone or with others) in a room that begins to fill with smoke, $75 \%$ of participants who waited alone reported the smoke in contrast to only $10 \%$ of participants who reported the event when they waited with two inactive confederate bystanders (Darley and Latané 1968).

In addition to looking to others for cues about whether or not to interpret a situation as an emergency, another complexity is the ambiguous nature of what constitutes bullying. Youth typically do not conceptualize bullying as it is defined (i.e., their definitions almost always omit the components of intentionality and repetition; Vaillancourt et al. 2008). When given an accurate definition of bullying, students generally report being victimized less, although boys tended to report bullying others more (Vaillancourt et al. 2008). Interpretation of the situation may also be influenced by how much a youth knows about a situation (Meter and Card 2015). For example, youth who have been victimized themselves are more likely to recognize victimization of their peers, likely due to heightened empathy and ability to perceive the other's distress (Perren et al. 2012; Pronk et al. 2014).

\section{Step 3: Accept Responsibility for the Situation}

When bystanders are present, one may assume that someone else will intervene, or that taking action (or blame for not taking action) will be diffused throughout the group, as opposed to specifically impacting the individual (Darley and Latané 1968). Diffusion of responsibility is compounded when there is not a cohesive group (Burn 2009; Rutkowski et al. 1983). The decision to take responsibility for action in sexual assault incidents has been linked to the social norms regarding intervention (Burn 2009; Rutkowski et al. 1983), as well as the perceived sense of community in the environment (Banyard 2008). Indeed, a prevalent societal norm that may relate to a failure to intervene in bullying is the idea of keeping to oneself and minding one's business (Bar-On 2001; Rigby and Johnson 2005).

Moral disengagement (cognitive reconstructing that leads one to view moral transgressions as benign or positive) and unconcerned feelings about bullying incidents are associated with passive bystander behavior (Pozzoli and Gini 2010, 2013). Attitudes and feelings toward the victim may also impact taking responsibility. Some youth report not helping because they think the victim deserves the bullying, which is consistent with the just world hypothesis 
(i.e., justifying the victimization of others by reasoning that the victim's behavior brought on the abuse, thus reducing one's own moral responsibility to act; Rigby and Johnson 2005). In contrast, empathy toward peers who were bullied is associated with intervening (Barchia and Bussey 2011; Caravita et al. 2009; Nickerson et al. 2008). Indeed, being aware of another's distress, experiencing negative emotions and reactivity may increase the likelihood of bystander intervention in bullying (Barhight et al. 2013; Perren et al. 2012; Pöyhönen et al. 2010; Pozzoli and Gini 2010). This may relate to one's own previous experience. Witnesses of bullying who have also been victimized report more social maladjustment (i.e., problems interacting with others) than witnesses who have not been victimized (Werth et al. 2015), yet higher self-reported victimization is also associated with a greater willingness to intervene (Batanova et al. 2014) in early adolescence.

\section{Step 4: Know How to Intervene or Provide Help}

The step of knowing what actions are needed in order to intervene effectively in a situation can be hampered by lack of intervention skills (Burn 2009), as well as low selfefficacy, or the belief that one can act in a way to achieve the intended goal (Anker and Feeley 2011; Banyard 2008). Social self-efficacy, having the competence to assert oneself in social situations, and problem-solving differentiate youth who intervene in bullying situations compared to those who do not (Gini et al. 2008; Pronk et al. 2013). Youth often believe that their possible actions will not be effective in counteracting bullying or that they will suffer retaliation from the perpetrator or other peers (Lodge and Frydenberg 2005; O'Connell et al. 1999; Rigby and Johnson 2005).

\section{Step 5: Implement Intervention Decisions}

The final step in the bystander intervention model is to intervene or help in the situation. Costs to the individual, in terms of time, danger, or effort, influence whether and how a person helps (Batson 1995; Piliavin et al. 1975). There are also gender differences in actions taken. For example, early research found that females were not as likely to help when a man collapsed (Piliavin et al. 1975). With regard to bystander intervention in bullying, actions may include direct efforts to make the student(s) bullying stop, or indirect interventions such as reporting the incident, asking a teacher or another adult for help, or supporting, consoling, or taking the side of the student(s) being victimized (Espelage et al. 2012; Huitsing and Veenstra 2012; Pronk et al. 2013). In addition, girls are more likely to tell a teacher, whereas boys are more likely to ignore bullying (Baldry 2005; Rigby and Johnson 2005; Rolider and
Ochayon 2005). More recent research indicates that girls are more likely to use indirect interventions whereas boys use more direct (Sijtsema et al. 2010). It is likely that the defending response is related to the extent to which it will be viewed favorably and if the person does not fear victimization as a result (Meter and Card 2015).

This model of bystander intervention, as applied to bullying, has great potential for shifting the norms and corresponding behaviors of youth. In order to advance the research and interventions, it is important to draw on the expertise of multiple disciplines. Mass communication, a field dedicated to applying theory and finding evidencebased solutions and using media campaigns to change attitudes and behaviors, is a logical fit for advancing research and bystander intervention using a multidisciplinary approach.

\section{Potential Contributions of Mass Communication to Bystander Intervention in Bullying}

The field of communication as a social science has at least two distinguishing features when compared to its peer disciplines (e.g., social psychology, sociology). First, the field started as a multidisciplinary effort at problem-solving and has since been concerned with applications of theory and evidence-based solutions. The national war efforts in the early 1940s drew social scientists from linguistics, sociology, and psychology, among other disciplines, to empirical research in a number of important areas, such as the study of propaganda effects and evaluation of promotional and recruitment efforts. In short, the Second World War provided the conditions for the beginnings of communication study (for review, see Rogers 1994). Second, communication has always had as its backdrop the industry of mass communication. Parallel with the beginnings and later growth of the new field was the rise of mass communication as an industry and a source of influence. Mass communication, whether it is radio, television, cinema, or the Internet, provides scholars with problems and opportunities for inquiry that evolve with changes in information technology (Schramm 1997).

There are two predominant paradigms in mass communication research that frame empirical research. One paradigm is concerned with the individual and his or her motivation(s) for choosing certain media and content over others. This paradigm that takes an active audience approach was pioneered by Blumler and Katz (1974) and assumes a theoretical link between the uses and gratifications of media. Research along this vein is concerned with the attributes of media (either real or perceived) and the functions they serve to users for psychological and social need fulfillment. This area is especially fertile of late with 
the seemingly limitless and low cost choices one has on television and the Internet (see Prior 2005). Relevant to the topic of bystander intervention, this first paradigm asks, "Why would a youth attend to mass media content centered on preventing bullying?"

The second paradigm is an effects perspective and examines the impact of media messages on individuals. This paradigm that takes a passive audience approach, initially termed the direct effects model, treats media as an exogenous factor, and suggests that media influence certain intended and unintended outcomes (Klapper 1960). Recent thinking in communication indicates a reciprocal relationship between individuals' predispositions and media exposure such that exposure is less than incidental as certain individuals (e.g., those inclined to violence) are more likely to choose certain types of media content (e.g., violent programming) that reinforces their pre-existing views. These choices, in turn, further shape personality in a spirallike fashion (see Slater 2007). Thus, in the case of targeting bystanders, it is important to consider how mass media campaigns reach youth who are more susceptible to being present in situations where bullying occurs, particularly knowing their general awareness and predispositions about bullying could inform the programs they may likely choose to consume.

Bullying presents communication scholars with several important areas of inquiry, and many have conducted research in this area (e.g., Brown and Witherspoon 2002; Cantor 2000). The goal of this section is to review the nature and potential of mass communication campaigns in targeting problems such as bullying. After reviewing this fecund area of scholarship in mass communication, several theories will be introduced in relation to their potential to inform multidisciplinary efforts for prevention through targeting one or more steps of the Latané and Darley's (1970) bystander intervention model.

\section{Mass Communication Campaigns}

The concept of a mass communication campaign is borrowed from the military sciences idea of a campaign, which indicates a strategic and usually large-scale plan conducted within a larger conflict or war. A mass communication campaign, similarly, has a specific goal or goals, targets a large number of individuals, is time-bound, and relies on an organized and strategic set of communication activities (Rogers and Storey 1987). Several principles guide effective mass communication campaigns that include the use of formative research to better understand context and the target audience and the use of multiple communication channels to gain wider message reach (Noar 2006). Perhaps most importantly, campaigns are based on theory and test hypotheses about why a given campaign or intervention is successful at bringing about change (e.g., attitudes, behaviors) in a target audience. Too often campaigns focus on dosage and message exposure and neglect to consider why a particular message design strategy works with a given audience. Consider Lasswell's (1948) classic model which asked, "Who says what, to whom, via what channels, with what effect?" Lasswell failed to account for why a given effect occurred or did not occur. Theories that address why mass communication campaigns would work in the prevention of bullying will be reviewed in the following section.

As mass communication campaigns vary greatly in their goals, target audience, message design, and context, likewise do results vary in published studies seeking to evaluate intervention impact. Snyder et al. (2009) identified a mean weighted effect of $r=.09$ for behavior change in their meta-analysis of 48 mass communication campaigns. A recent update on their procedures by Anker et al. (2016) found results varied by outcome factors with greater effects identified in campaigns seeking to increase knowledge $(r=.10)$ and smaller effects associated with behavior change $(r=.05)$. However, a better estimate of the value of mass communication campaigns should be conducted within a given health or social context, such as bullying prevention, due to the nuanced elements of any given area of interest. There is evidence that mass media campaigns have promise in decreasing elementary and middle school students' violence intentions and self-reported bullying behaviors (McLaughlin et al. 2006; Swaim and Kelly 2008). Therefore, although mass communication campaigns have small effects on behavior, they may be particularly useful for targeting knowledge of how to intervene in bullying, particularly if used according to the model described further below.

Some bullying prevention programs incorporate use of video to change norms and guide students in behavior change (e.g., Second Step: Student Success Through Prevention program, Committee for Children 2008). In fact, Ttofi and Farrington's (2011) meta-analysis revealed that one of the most important program elements in reducing victimization was using videos. However, many of these programs are geared toward youth in elementary and middle school without a focus on adolescence. There are also no known programs that focus specifically on the steps of the bystander intervention model integrating mass communication strategies.

There are many possibilities in relation to the five steps of Latané and Darley's (1970) bystander intervention model in terms of what the goal of a campaign might be in a targeted community. Before specifying a goal, formative research employing focus groups or structured interviews would inform where youth are in terms of the model. For 
example, do students notice and are they aware when bullying is occurring (Step 1)? If so, do they interpret the event as an emergency that requires help or intervention (Step 2)? Step 3 asks if students accept responsibility for intervening when they witness bullying and school violence, and campaigns might shape students' understanding of these issues in this regard. Perhaps the most important step to target in a campaign is how to intervene or provide help in a given school or community (Step 4). Each school may have its own rules as to how students ought to intervene when they witness bullying, and these rules should be made clear and reinforced through repeated messages. Finally, the action step (Step 5) involves the costs and benefits to intervening for the bystander, victim(s), and perpetrator(s). This step also could be targeted to encourage students who are reluctant to assist their peers due to either misunderstanding or lack of knowledge of such action steps. Of note, Evers et al. (2007), as part of their intervention that led to increased bystander intervention in bullying, assessed intentions and stages of change in relation to these concepts.

It is more likely the case that a given campaign or intervention would target multiple steps within the same message or across different messages due to their interlinking nature. For example, a message strategy might communicate bystanders' responsibility to intervene and the desired forms of intervention (i.e., how to help in an emergency) in a given school or community. It is also possible that a campaign could be longitudinal in nature and work through steps in sequence with pairs of steps targeted in blocks of time. To illustrate, a campaign could communicate the forms of bullying and the physical and psychological ramifications of these forms (i.e., Steps 1 and 2) in the first part of the campaign. The next part of the campaign could impress upon children that they are responsible to intervene and how they might intervene (Steps 3 and 4). Reinforcing earlier steps is also a useful tactic in campaigns seeking to move individuals from awareness to action.

\section{Theories of Mass Communication Influence}

There are multiple (e.g., more than 15) theories that potentially frame mass communication campaigns (Atkin and Rice 2013). In this, section we review three prominent theories of mass or public communication campaigns that inform efforts to reach and influence students with regard to bystander intervention in bullying.

\section{Agenda-Setting}

Media have the power to shape public and policy agendas, according to their agenda-setting function (McCombs and
Shaw 1972). While traditional mass communication campaigns typically design and deliver their own messages through designated media (e.g., TV ads, billboards), the agenda-setting function in a campaign indicates that traditional news media deliver these messages to readers or viewers, with policy makers and institutions pushing their social issues or agenda to the media for dissemination. As proponents of certain issues vie for media space, the agenda of the public is shaped by not only the number of stories pertaining to certain issues, but also the ways in which these issues are framed (Scheufele 1999, 2000). While agenda setting focuses on issue salience and framing considers issue attributes, scholars have also related these processes to priming, or the ways in which stories provide individuals with benchmarks to evaluate issues, to more comprehensively explore the range of cognitive campaign effects that may occur (Scheufele and Tewksbury 2007).

Taking into consideration that the media's agenda shapes policy holders and the public's agenda on given issues and, in turn, the policy agenda influences the media agenda in a reciprocal fashion, a concerted campaign to make bullying and bystanders prominent to the public (e.g., through news, entertainment, or social media) could potentially shape parents' and school administrators' agenda on the issue. The question moving forward is: What message frames should be used to best achieve the goals of a campaign? For example, if it is determined that students are still unsure of how to help during situations of bullying (Step 4 of bystander model), then stories might include an episode where a bystander assists in identifying a bully or bullies and acts appropriately (e.g., alerts the assistant principal) in supporting the victims. Furthermore, using particular message frames that focus on the rewards of these interventions (e.g., promoting the action as favorable and safe and the perpetrator as lacking popularity) while at the same time making these stories resonate with and appeal to adolescents would help encourage bystanders to implement these interventions in the real world (Step 5).

Clearly, other issues compete with bullying (e.g., drugs, truancy) on the policy agenda of schools, and the principles of agenda-setting indicate greater news coverage or stories about bystander intervention would make the issue more salient. At a minimum, greater coverage of the issue of bullying would indeed heighten awareness of the problem, and the use of story frames that highlight bullying as an emergency worthy of help would certainly increase the perceived severity of the issue, addressing the first two steps of the bystander intervention model.

\section{Entertainment-Education}

Entertainment-Education (E-E) is a promising line of inquiry for communication campaigns seeking to target 
bystanders to bullying. E-E grew out of the two extremes of trends in mass media-entertainment degradation programming and educational programming (Singhal and Rogers 1999). Entertainment degradation programming reduces a message to increase its entertainment attractiveness, very often through excessive use of sex, violence, and drugs. By contrast, educational programming can be unappealing as it may elicit boredom or provide minimal entertainment value for audiences. Somewhere between the two extremes, E-E intentionally places educational messages in an entertainment context (Singhal and Rogers 2002). An early example of E-E is Sesame Street that began in 1969 with the goal of both entertaining and educating disadvantaged children.

While E-E is better labeled a strategy than a theory, work by Moyer-Gusé (2008) explicates E-E as a theory of persuasion. E-E messages, when successful, reduce reactance and counterarguments among audience members, and at the same time increase perceived risk and self-efficacy through parasocial interactions with media figures. The use of $\mathrm{E}-\mathrm{E}$ to promote bystander intervention could be done through several means. Programming could target any one or a combination of the steps of the bystander intervention model through involvement with the narrative and/or media characters. Students transported into an engaging narrative may fully immerse themselves into the story, which shapes their beliefs in line with the messages (Green and Brock 2000) and increases narrative enjoyment (Green et al. 2004). As youth tend to seek guidance from and desire to be like characters with whom they perceive to be similar in attributes (e.g., smart, successful; Hoffner and Buchanan 2009), observing characters that are relatable with admirable traits intervening in a bullying situation is a powerful form of social modeling that has the potential to influence their knowledge of how to intervene and strengthen beliefs that they ought to intervene (i.e., social norms).

Thus, E-E programming could be developed to purposely influence youth along any of the five steps of the bystander intervention model. Alternatively, existing programming with storylines that illustrate bystander intervention in bullying could be shown to students on a regular basis during school hours and integrated within the school's curriculum. Research in local and international contexts has shown that prosocial content, such as messages targeting bullying prevention, embedded into entertainment programming can influence viewers' awareness of such problems and shape attitudes toward the advocated topic (e.g., bystander intervention in bullying) in a positive way. Campaigns that seek to influence bystander intervention in bullying could benefit from what has been learned through $\mathrm{E}-\mathrm{E}$ interventions at various levels in mass communication.

\section{Two-Step Flow of Mass Communication}

A third theoretical model focuses on the critical role individuals play in the influence process of mass communication. Too often do scholars take a simplified look at media effects and see the process as mechanistic, a oneway directional form of communication from the media source to the receiver. Katz and Lazarssfeld (1955) pioneered a model termed the two-step flow of media effects which considers the often neglected connection between mass media exposure and interpersonal communication. The theory is simple but elegant in its application: "ideas, often, seem to flow from radio and print to opinion leaders and from them to the less active sections of the population" (Katz and Lazarssfeld 1955, p. 32). It is likely this model is germane to the promotion of bystander intervention to bullying and school violence.

As the theory holds, mass communication campaigns, while targeting the general population, could influence opinion leaders or influencers who discuss the topic with peers and colleagues. Borrowing from the bystander intervention model, it could be the case that media campaigns target opinion leaders' (e.g., parents, teachers, administrators) sense of responsibility to help others. The forms of help are many and are likely presaged by conversations or other correspondences with policy makers and decision-makers related to students. In relation to messaging about suicide prevention, Aldrich and Cerel (2009) suggest that anyone who is close to an individual (e.g., other students, friend, relative) could be a target for intervention. Because peers are such powerful influences in bullying, they are primary targets of bystander intervention messaging.

It is suggested that exposure to some media content may boost conversation about the topic through increased topical understanding and conversational competency (Southwell and Torres 2006). In the case of promoting bystander intervention, it is likely that a novel approach that portrays the issue of bullying may bring about conversation about the issue-an issue relevant to adolescents and their parents. For example, the use of well-regarded celebrities (e.g., Demi Lovato, Lily Collins) in media campaigns against bullying (e.g., http://www.bystanderre volution.org) may be particularly effective as these media figures serve as inspirational role models who provide practical strategies for children and adolescents to "take the power out of bullying." Such efforts that include celebrity influencers to offer solutions for bystanders and bullies have popularized on a myriad of social networking platforms (e.g., YouTube, Facebook, Instagram), demonstrating the efficacy of the two-step flow of mass communication. Likewise, in light of today's social media climate, celebrities such as Ashton Kutcher who has a 
greater Twitter presence than even large media corporations such as CNN demonstrate the unique capacity of a single individual to produce a synergistic effect that capitalizes on both interpersonal and mass communication (Petersen 2009).

The application of the two-step flow model can also be considered in concert with agenda-setting and other models of mass communication campaign effects. For example, the media might set the audience members' agenda, who in turn, discuss the issue with critical others for a greater communitylevel effect. Other theories, such as social learning theory (Bandura 1977), can be considered to examine the mediating factors that account for campaign effects. Media campaigns can potentially shape youth's efficacy expectations (i.e., ability to help victims) through vicarious learning, modeling, and verbal persuasion. It is likely two or more theories of social influence are in operation when attempting to influence bystanders' thoughts and actions in relation to bullying. Alternatively, cultivation theory (Gerbner 1969) can inform potential long-term effects of mass media campaigns promoting bystander intervention on adolescents' social realities about bullying. Recent scholarship supports the positive psychological effects of exposure to meaningful media, particularly content emphasizing moral beauty and virtue, on viewers' feelings of elevation and altruistic motivations (Oliver et al. 2012a, b; Tsay-Vogel and Krakowiak, in press). Therefore, heavy doses of repetitive messages emphasizing the benefits of bystander intervention on the compassion and well-being of others could promote a kinder and more altruistic worldview rather than one focused predominantly on fear and violence.

\section{Research Considerations}

Research efforts would go far to fuse theories of social influence from communication scholars with what is known about bystander intervention. An important consideration in mass communication campaign design and evaluation is the use of focus groups and in-depth interviews with children to understand the context of the problem and to gain a richer understanding of campaign elements, such as message testing and exposure rates (see Noar 2006). This formative research helps identify relevant beliefs, as well as positive and negative outcomes of performing the behavior; it can also be used to develop messages and measures (Aldrich and Cerel 2009). After identification of which $\operatorname{step}(\mathrm{s})$ to target in the bystander intervention model, campaigns could work alone or in conjunction with in-school interventions to target bystander behavior in any of its forms.

In terms of content, campaigns would likely appeal to more than one step of the model to impress upon bystanders the importance of the situation and remind youth of their responsibility to assist victims. What is more, appeals would communicate the appropriate forms of help and their efficacy. Depending on the context, communication theories could potentially guide why a given campaign would be successful and this helps with successive replications of a given appeal by learning if and how an intervention worked toward realizing its stated aims. For example, communication scholars have examined moral disengagement in a media context, suggesting that viewers are likely to excuse characters who commit immoral actions for the sake of enjoying their mediated experience (Raney 2004). Research has shown that moral disengagement occurs with various entertainment offerings such as videogames (e.g., Hartmann and Vorderer 2010), films (Tsay-Vogel and Krakowiak 2016), and written narratives (Krakowiak and Tsay 2011; Tsay and Krakowiak 2011). Applied to bullying, studies have found that in films, bullies who display social aggressive behaviors are often portrayed as being popular and leading charming lives (e.g., see Behm-Morawitz and Mastro 2008). Moreover, in picture books made for preschoolers, bystanders are often portrayed as validating rather than aiding the victim and the responsibility of stopping bullies is placed primarily on victims rather than bystanders (Oppliger and Davis 2015). Therefore, avoiding moral disengagement cues by incorporating message attributes that facilitate greater moral engagement in mass media campaigns (e.g., demonstrating the moral incentives of bystander intervention and accepting personal responsibility for such actions) would greatly alter bystander behaviors from being passive to active.

It is also imperative that study designs rely upon repeated measures to identify the strength of a campaign given where children were prior to exposure to the mass media campaign. Also important is the use of paired or control schools or districts, depending on the scope of the campaign. Learning the extent to which an appeal worked given its cost is valuable to schools seeking to promote bystander intervention. The potential value of using mass communication appeals is that they can be cost-effective if you consider their reach and impact (Atkin and Rice 2013).

\section{Conclusion}

It is imperative that we consider a multidisciplinary approach when theorizing about and devising effective strategies for bystander intervention. Mass communication campaigns hold great potential in targeting problems such as bullying and violence prevention. Table 1 includes a summary of each step of Latané and Darley's (1970) bystander intervention model, its elements as applicable to 
Table 1 Integrating mass communication with the Bystander intervention model in bullying: potential applications

\begin{tabular}{|c|c|c|}
\hline Step & Elements & Message Strategy \\
\hline Jotice the event & $\begin{array}{l}\text { Attract attention to bullying as a problem } \\
\text { Recognize identifiable victims } \\
\text { Attend to relevant cues } \\
\text { Minimize distracting influences }\end{array}$ & $\begin{array}{l}\text { Use message cues to make bullying incidents (e.g., identification of victims and } \\
\text { bullies) more vivid to draw bystanders' attention } \\
\text { Use multiple media (e.g., music, television, film, and Internet) to reinforce } \\
\text { elements of bullying (e.g., power, repetition, and intent to harm) and aid in } \\
\text { salient information recall }\end{array}$ \\
\hline $\begin{array}{l}\text { Interpret event as } \\
\text { emergency }\end{array}$ & $\begin{array}{l}\text { View situation as emergency requiring } \\
\text { help } \\
\text { Look to others for cues [change norms] } \\
\text { Reduce ambiguity }\end{array}$ & $\begin{array}{l}\text { Use message frames that highlight the severity of bullying (e.g., harmful } \\
\text { consequences) to raise awareness of the issue and attribute it as worthy of } \\
\text { attention } \\
\text { Assess social norms and provide messages that emphasize social disapproval } \\
\text { and condemnation of bullying by peers }\end{array}$ \\
\hline $\begin{array}{l}\text { Accept } \\
\text { responsibility }\end{array}$ & $\begin{array}{l}\text { Take personal responsibility for } \\
\text { intervening } \\
\text { Avoid diffusion of responsibility } \\
\text { Elicit empathy for victim and emotional } \\
\text { reactivity }\end{array}$ & $\begin{array}{l}\text { Transport students into an engaging narrative to elicit empathy and emotional } \\
\text { reactivity } \\
\text { Use message frames that promote moral engagement (e.g., increase perceived } \\
\text { sense of community and encourage moral responsibility to intervene) }\end{array}$ \\
\hline $\begin{array}{l}\text { Know how to } \\
\text { intervene }\end{array}$ & $\begin{array}{l}\text { Increase social self-efficacy } \\
\text { Problem-solve about indirect and direct } \\
\text { actions to take } \\
\text { Recognize and plan to cope with possible } \\
\text { costs }\end{array}$ & $\begin{array}{l}\text { Use meaningful media to emphasize the moral beauty of helping others and the } \\
\text { benefits of bystander intervention to shape efficacy expectations } \\
\text { Incorporate relatable and admirable media figures to encourage wishful } \\
\text { identification and vicarious learning }\end{array}$ \\
\hline $\begin{array}{l}\text { Implement } \\
\text { intervention } \\
\text { decision }\end{array}$ & $\begin{array}{l}\text { Engage in indirect or direct behavior } \\
\text { appropriate and safe for the situation } \\
\text { Minimize costs associated with the } \\
\text { intervention }\end{array}$ & $\begin{array}{l}\text { Use media messages that positively reinforce cases of heroic and successful } \\
\text { bystander interventions and outcomes } \\
\text { Incorporate message frames that highlight personal stories of virtue and } \\
\text { altruism to increase volitional control among bystanders to act }\end{array}$ \\
\hline
\end{tabular}

bullying, and potential applications of mass communication in terms of message strategies.

The application of relevant communication theories to the development of media campaigns focused on raising awareness of and promoting bystander intervention can help identify not only what factors (e.g., media type, attributes of the message content) work, but also why these emotional, cognitive, and behavioral processes and effects take place. Although the theoretical models noted above invaluably inform multidisciplinary efforts to facilitate bullying prevention by targeting one or multiple steps of Latané and Darley's (1970) bystander intervention model, there are likely several alternative directions that may provide a more comprehensive understanding of the processes and effects underlying the bystander effect and offer practical preventative solutions to this social problem.

Acknowledgments We thank Melissa Dudley for her assistance with background research for this manuscript.

Authors' Contribution AN conceived of the concept and drafted the portions of the manuscript related to bullying, bystander intervention, and the table of potential applications. TF participated in the refinement of the concept and drafted the sections on mass communication campaigns targeting the bystander and theories of mass communication influence. MTV helped draft the mass communication campaign sections and the table of applications. All authors contributed to the research considerations and read and approved the final manuscript.

\section{Compliance with Ethical Standards}

Conflicts of interest The authors declare that they have no conflict of interest.

Ethical Approval This article does not contain any studies with human participants performed by any of the authors.

Informed Consent For this type of study, formal consent is not required.

\section{References}

Aldrich, R. S., \& Cerel, J. (2009). The development of effective message content for suicide intervention: Theory of planned behavior. Crisis: The Journal of Crisis and Suicide Prevention, 30, 174-179. doi:10.1027/0227-5910.30.4.174.

Anker, A. E., \& Feeley, T. H. (2011). Are non-participants in prosocial behavior merely innocent bystanders? Health Communication, 26, 13-24. doi:10.1080/10410236.2011.527618.

Anker, A. E., Feeley, T. H., McCracken, B., \& Lagoe, C. A. (2016). Measuring the effectiveness of mass-mediated health campaigns through meta-analysis. Journal of Health Communication, 21, 439-456. doi:10.1080/10810730.2015.1095820.

Atkin, C. K., \& Rice, R. E. (2013). Theory and principles of public communication campaigns. In R. E. Rice \& C. K. Atkin (Eds.), 
Public communication campaigns (pp. 3-19). Los Angeles, CA: Sage.

Baldry, A. C. (2005). Bystander behaviour among Italian students. Pastoral Care in Education, 23, 30-35. doi:10.1111/j.02643944.2005.00329.x.

Bandura, A. (1977). Self-efficacy: Toward a unifying theory of behavioral change. Psychological Review, 84, 191-215. doi:10. 1037/0033-295X.84.2.191.

Banyard, V. L. (2008). Measurement and correlates of pro-social bystander behavior: The case of interpersonal violence. Violence and Victims, 23, 85-99. doi:10.1891/0886-6708.23.1.83.

Barchia, K., \& Bussey, K. (2011). Predictors of student defenders of peer aggression victims: Empathy and social cognitive factors. International Journal of Behavior Development, 35, 289-297. doi:10.1177/0165025410396746.

Barhight, L. R., Hubbard, J. A., \& Hyde, C. T. (2013). Children's physiological and emotionalreactions to witnessing bullying predict bystander intervention. Child Development, 84, 375-390. doi:10.1111/j.1467-8624.2012.01839.x.

Bar-On, D. (2001). The bystander in relation to the victim and the perpetrator: Today and the holocaust. Social Justice Research, 14, 125-148. doi:10.1023/A:1012836918635.

Batanova, M., Espelage, D. L., \& Rao, M. A. (2014). Early adolescents' willingness to intervene: What roles do attributions, affect, coping, and self-reported victimization play? Journal of School Psychology, 52, 279-293. doi:10.1016/j.jsp.2014.02.001.

Batson, C. D. (1995). Prosocial motivation: Why do people help others? In A. Tesser (Ed.), Advanced social psychology (pp. 333-381). Boston: McGraw-Hill.

Behm-Morawitz, E., \& Mastro, D. E. (2008). Mean girls? The influence of gender portrayals in teen movies on emerging adults' genderbased attitudes and beliefs. Journal of Mass Communication Quarterly, 85, 131-146. doi:10.1177/107769900808500109.

Bibou-Nakou, I., Tsiantis, J., Assimopoulos, H., Chatzilambou, P., \& Giannakopolou, D. (2012). School factors related to bullying: A qualitative study of early adolescent students. Social Psychology of Education, 15, 125-145. doi:10.1007/s11218-012-9179-1.

Blumler, J. G., \& Katz, E. (1974). The uses of mass communications: Current perspectives on gratifications research. Beverly Hills, CA: Sage.

Brown, J. D., \& Witherspoon, E. M. (2002). The mass media and American adolescents' health. Journal of Adolescent Health, 31, 153-170. doi:10.1016/S1054-139X(02)00507-4.

Burn, S. M. (2009). A situational model of sexual assault prevention through bystander intervention. Sex Roles, 60, 779-792. doi:10. 1007/s11199-008-9581-5.

Cantor, J. (2000). Media violence. Journal of Adolescent Health, 27, 30-34. doi:10.1016/S1054-139X(00)00129-4.

Caravita, S., DiBlasio, P., \& Salmivalli, C. (2009). Unique and interactive effects of empathy and social status on involvement in bullying. Social Development, 18, 140-163. doi:10.1111/j. 1467-9507.2008.00465.x.

Committee for Children. (2008). Second step: Student success through prevention program. Seattle, WA: Committee for Children.

Cross, J. E., \& Peisner, W. (2009). RECOGNIZE: A social norms campaign to reduce rumor spreading in a junior high school. Professional School Counseling, 12, 365. doi:10.5330/PSC.n. 2010-12.365.

Darley, J. M., \& Latané, B. (1968). Bystander intervention in emergencies: Diffusion of responsibility. Journal of Personality and Social Psychology, 8, 377-383. doi:10.1037/h0025589.

Dillon, K. P., \& Bushman, B. J. (2014). Unresponsive or un-noticed: Cyberbystander intervention in an experimental cyberbullying context. Computers in Human Behavior, 45, 144-150. doi:10. 1016/j.chb.2014.12.009.
Dinkes, R., Kemp, J., Baum, K., \& Snyder, T. D. (2009). National center for education statistics: Indicators of school crime and safety: 2007. Retrieved from http://nces.ed.gov.

Dovidio, J. F., Piliavin, J. A., Schroeder, D. A., \& Penner, L. A. (2006). The social psychology of prosocial behavior. Mahwah, NJ: Lawrence Erlbaum Associates.

Endresen, I. M., \& Olweus, D. (2001). Self-reported empathy in Norwegian adolescents: Sex differences, age trends, and relationship to bullying. In A. C. Bohart, C. Arthur, \& D. J. Stipek (Eds.), Constructive and destructive behavior: Implications for family, school, and society (pp. 147-165). Washington, DC: American Psychological Association.

Espelage, D. L., Green, H. D., \& Polanin, J. R. (2012). Willingness to intervene in bullying episodes among middle school students: Individual and peer-group influences. Journal of Early Adolescence, 32, 776-801. doi:10.1177/0272431611423017.

Evers, K. E., Prochaska, J. O., Van Marter, D. F., Johnson, J. L., \& Prochaska, J. M. (2007). Transtheoretical-based bullying prevention effectiveness trials in middle schools and high schools. Educational Research, 49, 397-414. doi:10.1080/ 00131880701717271.

Faris, R., \& Felmlee, D. (2011). Status struggles: Network centrality and gender segregation in same-and cross-gender aggression. American Sociological Review, 76, 48-73. doi:10.1177/ 0003122410396196.

Faris, R., \& Felmlee, D. (2014). Casualties of social combat: School networks of peervictimization and their consequences. American Sociological Review, 79(2), 228-257. doi:10.1177/ 0003122414524573.

Gerbner, G. (1969). Toward cultural indicators: Analysis of mass mediated public message systems. AV Communication Review, 17, 137-148. doi:10.1007/BF02769102.

Gini, G., Albiero, P., Benelli, B., \& Altoè, G. (2008). Determinants of adolescents' active defending and passive bystanding behavior in bullying. Journal of Adolescence, 31, 93-105. doi:10.1016/j. adolescence.2007.05.002.

Gladden, R. M., Vivolo-Kantor, A. M., Hamburger, M. E., \& Lumpkin, C. D. (2014). Bullying surveillance among youths: Uniform definitions for public health and recommended data elements, version 1.0. Atlanta, GA: National Center for Injury Prevention and Control, Centers for Disease Control and Prevention and U.S. Department of Education.

Green, M. C., \& Brock, T. C. (2000). The role of transportation in the persuasiveness of public narratives. Journal of Personality and Social Psychology, 79(5), 701-721. doi:10.1037/0022-3514.79. 5.701.

Green, M. C., Brock, T. C., \& Kaufman, G. F. (2004). Understanding media enjoyment: The role of transportation into narrative worlds. Communication Theory, 4, 311-327. doi:10.1111/j.14682885.2004.tb00317.x.

Greitemeyer, T., Fischer, P., Kastenmüller, A., \& Frey, D. (2006). Civil courage and helping behavior: Differences and similarities. European Psychologist, 11, 90-98. doi:10.1027/1060-9040.11.2. 90.

Hartmann, T., \& Vorderer, P. (2010). It's okay to shoot a character: Moral disengagement in violent video games. Journal of Communication, 60, 94-119. doi:10.1111/j.1460-2466.2009. 01459.x.

Hillebrand-Gun, T., Heppner, M. J., Mauch, P. A., \& Park, H. J. (2010). Men as allies: The efficacy of a high school rape prevention intervention. Journal of Counseling and Development, 88, 43-51. doi:10.1002/j.1556-6678.2010.tb00149.x.

Hoffner, C., \& Buchanan, M. (2009). Young adults' wishful identification with television characters: The role of perceived similarity and character attributes. Media Psychology, 7, 325-351. doi:10.1207/S1532785XMEP0704_2. 
Hughes, C., Julian, R., Richman, M., Mason, R., \& Long, G. (2008). Harnessing the power of perception: Reducing alcohol-related harm among rural teenagers. Youth Studies Australia, 27, 26-36.

Huitsing, G., \& Veenstra, R. (2012). Bullying in classrooms: Participant roles from a social network perspective. Aggressive Behavior, 38, 494-509. doi:10.1002/ab.21438.

Jeffrey, L. R., Miller, D., \& Linn, M. (2001). Middle school bullying as context for the development of passive observers to the victimization of others. Journal of Emotional Abuse, 2, 143-156. doi:10.1300/J135v02n02_09.

Jones, S. E., Bombieri, L., Livingstone, A. G., \& Manstead, A. S. R. (2012). The influence of norms and social identities on children's responses to bullying. British Journal of Educational Psychology, 82, 241-256. doi:10.1111/j.2044-8279.2011.02023.x.

Juvonen, J., \& Graham, S. (2014). Bullying in schools: The power of bullies and the plight of victims. The Annual Review of Psychology, 65, 159-185. doi:10.1146/annurev-psych-010213115030.

Katz, E., \& Lazarssfeld, P. F. (1955). Personal influence. New Brunswick, NJ: Transaction Publishers.

Klapper, J. T. (1960). The effects of mass communication. New York: The Free Press.

Krakowiak, K. M., \& Tsay, M. (2011). The role of moral disengagement in the enjoyment of real and fictional characters. International Journal of Arts and Technology, 4, 90-101.

Lasswell, H. D. (1948). The structure and function of communication in society. In L. Bryson (Ed.), The communication of ideas: A series of addresses (pp. 243-276). New York: Harper.

Latané, B., \& Darley, J. M. (1970). The unresponsive bystander: Why doesn't he help?. Englewood Cliffs, NJ: Prentice Hall.

Lodge, J., \& Frydenberg, E. (2005). The role of peer bystanders in school bullying: Positive steps toward promoting peaceful schools. Theory into Practice, 44, 329-336. doi:10.1207/ s1543052tip4404_6.

Loewenstein, G., \& Small, D. A. (2007). The scarecrow and the tin man: The vicissitudes of human sympathy and caring. Review of General Psychology, 11, 112-126. doi:10.1037/1089-2680.11.2. 112.

McCombs, M. E., \& Shaw, D. L. (1972). The agenda-setting function of the mass media. Public Opinion Quarterly, 36, 176-187.

McLaughlin, L., Laux, J. M., \& Pescara-Kovach, L. (2006). Using multimedia to reduce bullying and victimization in third-grade urban schools. Professional School Counseling, 10(2), 153-160. doi:10.5330/prsc.10.2.u4r784873j6h8t87.

Meter, D. J., \& Card, N. A. (2015). Defenders of victims of peer aggression: Interdependence theory and an exploration of individual, interpersonal, and contextual effects on the defender participant role. Developmental Review, 38, 222-240. doi:10. 1016/j.dr.2015.08.001.

Moyer-Gusé, E. (2008). Toward a theory of entertainment persuasion: Explaining the persuasive effects of entertainment-education messages. Communication Theory, 18, 407-425. doi:10.1111/j. 1468-2885.2008.00328.x.

Nickerson, A. B., Aloe, A. M., Livingston, J. A., \& Feeley, T. H. (2014). Measurement of the bystander intervention model for bullying and sexual harassment. Journal of Adolescence, 37, 391-400. doi:10.1016/j.adolescence.2014.03.003.

Nickerson, A. B., Cornell, D. G., Smith, D., \& Furlong, M. (2013). School antibullying efforts: Advice for policymakers. Journal of School Violence, 12, 268-282. doi:10.1080/15388220.2013. 787366.

Nickerson, A. B., Mele, D., \& Princiotta, D. (2008). Attachment and empathy as predictors of roles as defenders or outsiders in bullying situations. Journal of School Psychology, 46, 687-703. doi:10.1016/j.jsp.2008.06.002.
Nickerson, A. B., \& Nagle, R. J. (2005). Parent and peer attachment in late childhood and early adolescence. Journal of Early Adolescence, 25, 223-249. doi:10.1177/0272431604274174.

Noar, S. M. (2006). A 10-year retrospective of research in health mass media campaigns: Where do we go from here? Journal of Health Communication, 11, 21-42. doi:10.1080/10810730500461059.

O'Connell, P., Pepler, D., \& Craig, W. (1999). Peer involvement in bullying: Insights and challenges for interventions. Journal of Adolescence, 22, 437-452. doi:10.1006/jado.1999.0238.

Oliver, M. B., Hartmann, T., \& Woolley, J. K. (2012a). Elevation in response to entertainment portrayals of moral virtue. Human Communication Research, 38, 360-378. doi:10.1111/j.14682958.2012.01427.x.

Oliver, M. B., Krakowiak, K. M., \& Tsay, M. (2012). Elevating entertainment and the "kind-world" syndrome. In Paper presented at the 62nd annual conference of the International Communication Association, Phoenix, AZ.

Oppliger, P. A., \& Davis, A. (2015). Portrayals of bullying: A content analysis of picture books for preschoolers. Early Childhood Education Journal. doi:10.1007/s10643-015-0734-1.

Paluck, E. L., \& Shepherd, H. (2012). The salience of social referents: A field experiment on collective norms and harassment behavior in a school social network. Journal of Personality and Social Psychology, 103(6), 899-915. doi:10.1037/a0030015.

Perkins, H. W., Craig, D. W., \& Perkins, J. M. (2011). Using social norms to reduce bullying: A research intervention among adolescents in five middle schools. Group Processes \& Intergroup Relations, 14, 703-722. doi:10.1177/1368430210398004.

Perren, S., Gutzwiller-Helfenfinger, E., Malti, T., \& Hymel, S. (2012). Moral reasoning and emotion attributions of adolescent bullies, victims and bully-victims. British Journal of Developmental Psychology, 30, 511-530. doi:10.1111/j.2044-835X.2011.02059. $\mathrm{x}$.

Petersen, A. H. (2009). 'We're making our own paparazzi': Twitter and the construction of star authenticity. Flow-A Critical Forum on Television and Media Culture, 9, 14.

Piliavin, I. M., Piliavin, J. A., \& Rodin, J. (1975). Costs, diffusion, and the stigmatized victim. Journal of Personality and Social Psychology, 32, 429-438. doi:10.1037/h0077092.

Polanin, J. R., Espelage, D. L., \& Pigott, T. D. (2012). A metaanalysis of school-based bullying prevention programs' effects on bystander intervention behavior. School Psychology Review, $41,47-65$.

Pöyhönen, V., Juvonen, J., \& Salmivalli, C. (2010). What does it take to defend the victimized peer? The interplay between personal and social factors. Merrill-Palmer Quarterly, 56, 143-163. doi: $10.1353 / \mathrm{mpq} \cdot 0.0046$.

Pozzoli, T., \& Gini, G. (2010). Active defending and passive bystanding behavior in bullying: The role of personal characteristics and perceived peer pressure. Journal of Abnormal Child Psychology, 38, 815-827. doi:10.1007/s10802-010-9399-9.

Pozzoli, T., \& Gini, G. (2013). Friend similarity in attitudes toward bullying and sense of responsibility to intervene. Social Influence, 8, 161-176. doi:10.1080/15534510.2012.716372.

Prior, M. (2005). News vs. entertainment: How increasing media choice widens gaps in political knowledge and turnout. American Journal of Political Science, 49, 577-592. doi:10.1111/j. 1540-5907.2005.00143.x.

Pronk, J., Goossens, F. A., Olthof, T., De May, L., \& Willemen, A. M. (2013). Children's intervention strategies of victimization by bullying: Social cognitions of outsiders versus defenders. Journal of School Psychology, 51, 669-682. doi:10.1016/j.jsp. 2013.09.002.

Pronk, J., Olthof, T. G., \& Goossens, F. A. (2014). Factors influencing interventions on behalf of victims of bullying: A counterfactual 
approach to the social cognitions of outsiders and defenders. Journal of Early Adolescence, . doi:10.1177/0272431614562836.

Rabow, J., Newcomb, M., Monto, M., \& Hernandez, A. (1990). Altruism in drunk driving situations: Personal and situational factors in intervention. Social Psychology Quarterly, 53, 199-213. doi:10.2307/2786959.

Raney, A. A. (2004). Expanding disposition theory: Reconsidering character liking, moral evaluations, and enjoyment. Communication Theory, 14, 348-369. doi:10.1111/j.1468-2885.2004. tb00319.x.

Rigby, K., \& Johnson, B. (2005). Student bystanders in Australian schools. Pastoral Care in Education, 23, 10-16. doi:10.1111/j. 0264-3944.2005.00326.x.

Rodkin, P. C., \& Hodges, E. V. E. (2003). Bullies and victims in the peer ecology: Four questions for psychologists and school professionals. School Psychology Review, 32, 384-400.

Rogers, E. M. (1994). A history of communication study: A biographical approach. New York: The Free Press.

Rogers, E. M., \& Storey, J. D. (1987). Communication campaigns. In C. R. Berger \& S. H. Chaffee (Eds.), Handbook of communication science (pp. 817-846). Beverly Hills, CA: Sage.

Rolider, A., \& Ochayon, M. (2005). Bystander behaviors among Israel children witnessing bullying behavior in school settings. Pastoral Care in Education, 23, 36-39. doi:10.1111/j.0264-39.

Rutkowski, G. K., Gruder, C. L., \& Romer, D. (1983). Group cohesiveness, social norms, and bystander intervention. Journal of Personality and Social Psychology, 44, 545-552. doi:10.1037/ 0022-3514.44.3.545.

Salmivalli, C. (2010). Bullying and the peer group: A review. Aggression and Violent Behavior, 15, 112-120. doi:10.1016/j. avb.2009.08.007.

Salmivalli, C., \& Voeten, M. (2004). Connections between attitudes, group norms, and behaviors associated with bullying in schools. International Journal of Behavioral Development, 28, 246-258. doi:10.1111/1467-9450.00040.

Scheufele, D. A. (1999). Framing as a theory of media effects. Journal of Communication, 49(1), 103-122. doi:10.1111/j.14602466.1999.tb02784.x.

Scheufele, D. A. (2000). Agenda-setting, priming, and framing revisited: Another look at cognitive effects of political communication. Mass Communication \& Society, 3, 297-316.

Scheufele, D. A., \& Tewksbury, D. (2007). Framing, agenda setting, and priming: The evolution of three media effects models. Journal of Communication, 57, 9-20. doi:10.1207/ S15327825MCS0323_07.

Schramm, W. (1997). The beginnings of communication study in America. Thousand Oaks, CA: Sage.

Sijtsema, J. J., Ojanen, T., Veenstra, R., Lindenberg, S., Hawley, P. H., \& Little, T. D. (2010). Forms and functions of aggression in adolescent friendship selection and influence: A longitudinal social network analysis. Social Development, 19(3), 515-534. doi:10.1111/j.1467-9507.2009.00566.x.

Singhal, A., \& Rogers, E. M. (1999). Entertainment-education: A communication strategy for social change. Mahwah, NJ: Erlbaum.

Singhal, A., \& Rogers, E. M. (2002). A theoretical agenda for entertainment-education. Communication Theory, 12(2), 117-135. doi:10.1111/j.1468-2885.2002.tb00262.x.
Slater, M. D. (2007). Reinforcing spirals: The mutual influence of media selectivity and media effects and their impact on individual behavior and social identity. Communication Theory, 17, 281-303. doi:10.1111/j.1468-2885.2007.00296.x.

Snyder, L. B., Hamilton, M. A., \& Huedo-Medina, T. (2009). Does evaluation design impact communication campaign effect size? A meta-analysis. Communication Methods and Measures, 3, 84-104. doi:10.1080/19312450902809722.

Southwell, B. G., \& Torres, A. (2006). Connecting interpersonal and mass communication: Science news exposure, perceived ability to understand science, and conversation. Communication Monographs, 73(3), 334-350. doi:10.1080/03637750600889518.

Stuart-Cassel, V., Bell, A., \& Springer, J. F. (2011). Analysis of state bullying laws and policies. Folsom, CA: EMT Associates.

Swaim, R. C., \& Kelly, K. (2008). Efficacy of a randomized trial of a community and school-based anti-violence media intervention among small-town middle school youth. Prevention Science, 9, 202-214. doi:10.1007/s11121-008-0096-7.

Tsay, M., \& Krakowiak, K. M. (2011). The impact of perceived character similarity and identification on moral disengagement. International Journal of Arts and Technology, 4, 102-110. doi:10.1504/IJART.2011.037773.

Tsay-Vogel, M., \& Krakowiak, K. M. (2016). Effects of hedonic and eudaimonic motivations on film enjoyment through moral disengagement. Communication Research Reports, 33(1), 54-60. doi:10.1080/08824096.2015.1117443.

Tsay-Vogel, M., \& Krakowiak, K. M. (in press). Can watching reality TV motivate you to be more altruistic? Examining the prosocial effects of lifestyle transforming reality programs. Journal of Broadcasting \& Electronic Media.

Ttofi, M. M., \& Farrington, D. P. (2011). Effectiveness of schoolbased programs to reduce bullying: A systematic and metaanalytic review. Journal of Experimental Criminology, 7, 27-56. doi:10.1007/s11292-010-9109-1.

Unnever, J. D., \& Cornell, D. G. (2004). Middle school victims of bullying: Who reports being bullied? Aggressive Behavior, 30, 373-388. doi:10.1002/ab.20030.

Vaillancourt, T., McDougall, P., Krygsman, A., Hymel, S., Miller, J., Stiver, K., \& Davis, C. (2008). Bullying: Are researchers and children/youth talking about the same thing? International Journal of Behavioral Development, 32, 486-495. doi:10.1177/ 0165025408095553.

Wang, J., Iannotti, R. J., \& Nansel, T. R. (2009). School bullying among adolescents in the United States: Physical, verbal, relational and cyber. Journal of Adolescent Health, 45, 368-375. doi:10.1016/j.jadohealth.2009.03.021.

Werth, J. M., Nickerson, A. B., Aloe, A. M., \& Swearer, S. M. (2015). Bullying victimization and the social and emotional maladjustment of bystanders: A propensity score analysis. Journal of School Psychology, 53, 295-308. doi:10.1016/j.jsp.2015.05.004.

Yeager, D. S., Fong, C. J., Lee, H. Y., \& Espelage, D. L. (2015). Declines in efficacy of anti-bullying programs among older adolescents: Theory and a three-level meta-analysis. Journal of Applied Developmental Psychology, 37, 36-51. doi:10.1016/j. appdev.2014.11.005. 